\title{
FREEDOM TO ROAM
}

\author{
Matthias Brinkmann
}

$\prod$

N THIS PAPER, I look at the right to roam, which is the right of the public to access private lands. This might sound oxymoronic. Is it not in the nature of private property that owners can exclude whomever they want, under a wide range of circumstances? Can you even be considered to fully own anything if you do not have the right to say no to others accessing it? Assumptions in favor of property owners' rights to exclude are deeply ingrained in American law and many other legal systems, are accepted widely by left-liberal philosophers, and are part of a prephilosophical view of private property. ${ }^{1}$

By contrast, the Swedish allemansrätten ("everyman's right") gives everyone the right to walk freely across any part of the Swedish countryside; a right to pick wild berries, mushrooms, and flowers; and a right to swim or boat in lakes and rivers. It also extends beyond walking to biking, skiing, and horseback riding. There are limits to the right: roamers must respect the privacy of landowners, must stay away from houses and their curtilage, and must not damage the land - in particular, they must not cross fields or other agriculturally used lands. But crucially, all land, whether privately or publicly owned, is subject to the allemansrätten: landowners have no rights to exclude roamers or to put up fences or other obstacles.

The right to roam is an established legal right in other countries too, primarily in Scandinavia, but weaker versions of it can also be found in some northern European countries, such as Switzerland, England, and Scotland. However, there has been no serious philosophical reflection on this right-not a single treatment in a philosophical journal. The right to roam has been discussed in legal journals, where it is a minor theater in the larger war about the right to exclude

1 There are many exceptions we can ignore. For example, the right of owners to exclude is more circumscribed where their property is used in "quasi-public" ways-e.g., shopping malls, restaurants, and hotels (Gray and Gray, "Civil Rights, Civil Wrongs and Quasi-Public Space”). 
in property law. ${ }^{2}$ While there is much to like in this literature, a focus on law can quickly make us lose sight of the important philosophical issues.

In this paper, I offer a general defense of the right to roam. First, I give a brief overview of how the right to roam is understood and implemented in existing legal systems (section 1). Then, I show that defending the right to roam on broadly liberal grounds is quite difficult, as an interest-based defense of the right fails (section 2) and a left-liberal view of property rights favors rights to exclude (section 3). Notwithstanding these difficulties, I suggest that the right to roam can be defended on nonideal grounds (section 4 ): it has symbolic value, reminding the haves of their fundamentally equal co-ownership of the world with the havenots (sections 5 and 6).

\section{THE RIGHT TO ROAM}

At a minimum, the right to roam is the right to traverse certain parts of the countryside on foot, irrespective of the ownership of these lands, as long as one respects the privacy of the owners and traverses responsibly and without damaging the land. A corresponding duty of landowners is that they not impede roamers - that they not put up fences and signs or other obstacles keeping roamers out. The right to roam generally excludes motorized transport, but it may extend to biking, horseback riding, swimming, hiking, and canoeing.

All countries with a right to roam exclude houses and their curtilage (the identifiable area belonging to a house, such as gardens, sheds, and patios) from its scope, and it is generally understood that roamers must respect the privacy of owners-for example, by keeping a certain distance from houses. ${ }^{3}$ A second common restriction concerns land used for agricultural purposes. The Norwegian Outdoor Recreation Act, for example, excludes "farmyards, plots around houses and cabins, tilled fields, hay meadows, cultivated pasture, young plantations and similar areas," and permits traversing those areas only under restrictive circumstances. ${ }^{4}$

2 The most philosophically helpful paper, which I will engage with below, is Anderson, "Britain's Right to Roam." See also Lovett, "Progressive Property in Action." Other references to the legal literature can be found throughout. For an account of the wider issues in property law, see Klick and Parchomovsky, "The Value of the Right to Exclude"; and Wyman, "The New Essentialism in Property." Useful defenses of roaming aimed toward a popular audience can be found in Shoard, Right to Roam; and Ilgunas, This Land Is Our Land.

3 English law, e.g., imposes a minimum distance of twenty meters to be kept from houses (Countryside and Rights of Way Act, 2000, c. 37, sch. 1, pt. 1, para. 3).

4 Lov om friluftslivet [Outdoor Recreation Act], July 1, 1957, art. 1a (Norway), https://www. regjeringen.no/en/dokumenter/outdoor-recreation-act/id172932/. 
Beyond this shared core, we can broadly distinguish two models of the right to roam: the Scandinavian model, which recognizes strong, far-reaching, and relatively open-ended rights to roam the countryside, and the northern European model, which recognizes only weaker and limited rights to roam. The former is the more interesting, and the one I will aim to defend. ${ }^{5}$

The right to roam in the northern European model tends to be a narrow right to walk across certain types of lands. A case in point is English law, which recognizes a right to walk across so-called access lands in the Countryside and Rights of Way Act 2000. Only about 6.5 percent of English land is classified as such, however, and only certain types of land can become access lands-specifically, mountains, moor, heath, down, and coastal lands. ${ }^{6}$ Moreover, the act includes a wide number of exceptions. For example, lakes and rivers are excluded, as are golf courses and "land habitually used for the training of racehorses." Activity on access lands is also restricted to walking; most other recreational activities, such as camping, hiking, flower picking, and horseback riding, are excluded.

The English case is representative of other legal jurisdictions, like Germany's, Switzerland's, or Denmark's. In these legal systems, the right to roam exists only in heavily circumscribed forms and does not cover much more than a right to walk across specified types of land. Germany, for example, recognizes no general right to roam but grants a right to freely access forests, as does Austria. ${ }^{7}$ Switzerland gives everyone a right to access forests and meadows, as well as uncultivable land such as the high alpine mountains. ${ }^{8}$

5 The labels for the two models are not meant to suggest precise geographical boundaries: Denmark's situation is more akin to the northern European model, while Finland and, to a degree, Scotland adopt the Scandinavian model.

6 Klick and Parchomovsky, "The Value of the Right to Exclude," 949. Gray gives the number as 12 percent ("Pedestrian Democracy and the Geography of Hope," 48).

7 Gesetz zur Erhaltung des Waldes und zur Förderung der Forstwirtschaft (Bundeswaldgesetz, BWaldG), May 2, 1975, Bundesgesetzblatt [BGBl] I at 1037, as amended, art. 14 (Germany), https://www.gesetze-im-internet.de/bwaldg/BJNRo10370975.html; Bundesgesetz vom 3. Juli 1975, mit dem das Forstwesen geregelt wird (Forstgesetz, ForstG), July 3, 1975, Bundesgesetzblatt [BGBl] No. 440/1975, as amended, art. 33 (Austria), https://www.ris.bka. gv.at/GeltendeFassung.wxe?Abfrage $=$ Bundesnormen \&Gesetzesnummer $=10010371$.

8 Schweizerisches Zivilgesetzbuch (ZGB), December 10, 1907, SR 210, as amended, art. 699 (Switzerland), https://www.fedlex.admin.ch/eli/cc/24/233-245_233/de\#art_699; Bundesgesetz über den Wald (Waldgesetz, WaG), October 4, 1991, SR 921.0, as amended, art. 14 (Switzerland), https://www.fedlex.admin.ch/eli/cc/1992/2521_2521_2521/de\#art_14.

For an overview of different European jurisdictions, see Robertson, "Public Access to Private Land for Walking." Even within the United States, feeble cousins of a right to roam exist, such as laws regulating access to beaches in certain states (Rose, "The Comedy of the Commons"). See also Sawers, "The Right to Exclude from Unimproved Land." 
In the Scandinavian model, by contrast, the right to roam is much broader and far ranging. The Swedish allemansrätten, for example, allows one to camp on private land and to build campfires; to pick berries, flowers, and mushrooms; and to use alternate modes of transportation like skiing and horseback riding. Moreover, the allemansrätten is often seen as a common right, predating the legal system. Thus, most of the rules governing the allemansrätten are not actually found in positive law, but rather at the level of social convention. Consequently, guidance on the allemansrätten tends to be framed vaguely, in terms of open-ended guidelines, and often appeals to common sense and respect for nature and others. ${ }^{9}$

The right to roam must be distinguished from at least one related legal phenomenon. Easements grant someone a right to traverse someone else's land for a specified purpose. ${ }^{10}$ In the paradigm case, $A$ 's only means of accessing a public road from their property is via $B$ 's land-in extremis you can imagine that $B$ 's land surrounds $A$ 's like a donut. ${ }^{11}$ In such a case, almost all jurisdictions will grant $A$ the right to traverse $B$ 's land to access the public road. But while both the right to roam and easements grant access to others' private land, easements are highly localized and vested in particular people for a particular purpose. For example, if $A$ 's land became directly connected to a public road, their right to traverse $B$ 's land would cease; nor could $A$ stray freely from the path that is strictly necessary for them to reach public roads.

\section{THE INSUFFICIENCY OF INTERESTS IN ROAMING}

In the jurisdictions where it exists, the right to roam is designed to strike a balance between the interests of landowners and the interests of roamers. The public is given an opportunity for recreation and leisure, while landowners' economic and privacy interests remain largely protected. If the right to roam wears any justification on its sleeve, it is this balancing of competing interests. For this reason, it is useful to start with considering the interests roaming serves and whether they are strong enough to justify legally recognizing a right to roam.

Jerry Anderson identifies six relevant interests of roamers: (i) transportation, (ii) enjoyment of nature, (iii) physical health, (iv) mental health, (v) connection to history and culture, and (vi) sense of community. ${ }^{12}$ On the basis of any of

For a brief overview of allemansrätten, see Sténs and Sandström, “Allemansrätten in Sweden." miniak, "Must Right-Libertarians Embrace Easements by Necessity?" 
these interests, or some combination of them, so the hope goes, we can justify a right to roam. Our aim is specifically to establish the freedom to roam as a right, not merely as a desirable policy objective. Within a liberal framework, listing a set of interests that roamers have is insufficient, by itself, to establish roaming as a right.

However, we have a ready-made and widely accepted theory of rights at hand that allows us to make the connection: the interest theory of rights. ${ }^{13}$ According to this theory, if an interest satisfies certain criteria - for example, if it is important enough, broadly shared, and feasible to protect through legal means - then it grounds a corresponding right. ${ }^{14}$ Note that this is the most sympathetic ground on which we can consider the issue. On alternative theories of rights, such as a status theory of rights, the right to roam is likely to be harder to defend.

The crux of the matter, then, rests on whether the interests in roaming proposed by Anderson and others fulfill the relevant criteria. I will not develop a full account of what these criteria are. However, there are at least three minimal criteria that any plausible liberal version of the interest theory will recognize:

1. Strength criterion: The relevant interests must be morally important enough to justify imposing duties on others.

2. Neutrality criterion: The relevant interests must be compatible with the state remaining neutral between different conceptions of the good life: all reasonable people must be able to agree that these interests are worth protecting and serving through the state.

3. Necessity criterion: If the relevant interests are meant to justify a right to $X$, then $X$ must be practically necessary for serving the intereststhere can be no alternative institutional scheme that similarly serves the interest but has significantly lesser moral costs.

These three commitments will become clearer as we go along. My central claim is that none of Anderson's six interests, and no combination of them, fulfills these three criteria.

13 The classic account is Raz, "On the Nature of Rights." A good discussion of Raz's theory, specifically with a view toward property rights, is Cruft, "Against Individualistic Justifications of Property Rights." For an interest theory of human rights, see Tasioulas, "On the Foundations of Human Rights."

14 This means that I use the interest theory as a theory of the justification of rights (as, e.g., Tasioulas does), not as a theory about the nature (e.g., Kramer, "Some Doubts about Alternatives to the Interest Theory of Rights") or directionality (e.g., Sreenivasan, "Duties and Their Direction") of rights. 


\subsection{Means of Transportation}

We can start with Anderson's first proposed interest in a right to roam, roaming as a means of transportation. There is an immediate worry stemming from this interest not being strong enough in the average member of the public. The right to roam, after all, primarily applies within a rural context, and it generally does not cover motorized transport. But it is hard to think that there are many people who regularly need to roam across private, rural lands to move between, say, home and work, at least if we think of rich, urbanized societies.

Thus, from the start, this interest is not strong enough to justify a right to roam (although it might justify, say, a right to a public system of roads). The interest theory certainly cannot allow for every interest, no matter how weak, to translate into a right. After all, rights correspond to duties (or other types of Hohfeldian incidents), which demand fulfillment above any other practical concerns. Only important and widely shared interests can serve as a ground for a right, if we want to avoid extreme proliferation of rights. ${ }^{15}$

One might reply that some people and some groups have a strong interest to roam as a means of transportation, even if that interest is not widely shared. ${ }^{16}$ We can imagine a rural town in which the only plausible way to get to the market or to the factory or to church is by walking through the holdings of a large landowner. Would this not be a sufficiently strong interest to justify a right to roam? The problem with this response is that we now run afoul of the necessity requirement. We can acknowledge that specific groups of people need specific kinds of access to specific lands to fulfill important needs. But surely, granting a general right to roam - that is, a right for everyone to roam any kind of private land-would be a huge overreaction to such localized needs. This argument at best justifies specific easements, not a right to roam.

The idea behind the necessity requirement is that rights should be tailored to the interests they serve. They should cover all that is necessary for protecting and promoting the interests, but not more-especially if there are feasible alternatives that are more tailored for the relevant purpose. Once again, we want to be conservative, both philosophically and practically, in multiplying rights. Rights take primacy in our moral reasoning, imposing side constraints on how we can act and (in the case of positive rights) duties of provision. Given these considerations, it is morally preferable to deal with transportation-based interests in roaming by allowing easements, rather than by granting a general right to roam. 


\subsection{Enjoyment of Nature}

We can see the necessity criterion in action, in a different way, when it comes to roaming as a means of enjoying nature. While not everyone feels the urge to explore nature, walking, biking, and camping in nature are an important element of welfare for many. Let us accept, perhaps generously, that this interest satisfies the strength criterion.

However, consider two alternatives to the right to roam. The first institutional arrangement is a system of public parks and other publicly provided spaces. Under this arrangement, the state provides for an abundance of freely accessible spaces, both in nature and in cities. The state might fund natural parks-for example, Shenandoah National Park in Virginia. Alternatively, some land might be set aside as "commons," such as Port Meadow in Oxford. On well-administered versions of such schemes, there would be many diverse and geographically dispersed sites, all easily accessible to the public.

We can also imagine a different arrangement that rests on public-private partnerships. Perhaps the state offers a less extensive array of public parks, but it encourages landowners to open up their land to the public. The state might offer small financial rewards to landowners for registering their land as being accessible to roamers, or it might make other legal rules that encourage landowners to open up their lands - for example, through favorable tax treatment. Information on which private lands are publicly accessible would be made available in some central place, such as a government website. ${ }^{17}$

Contrast these two schemes with the right to roam, through the specific lens of how they serve an interest in enjoying nature. The following strikes me as true: (i) these two alternative schemes, if implemented reasonably well, will sufficiently serve our interest in enjoying nature, and (ii) these schemes have lesser moral costs than an institutionalized right to roam, because they rest on public or consensual provision of access to land while respecting the autonomy of property owners. These two claims, taken together, mean that enjoyment of nature fails the necessity criterion for establishing a right to roam.

One might respond that a right to roam better serves the relevant interest than these alternative schemes. You might reply, for example, that public parks are harder and more difficult to access, while roaming can often start right from your doorstep. But the relevant question is not whether these alternative schemes best serve the interest, but whether they serve it reasonably well. A theory that gives us a right to those means that best serve our interests rather than a right to plausible means would be much too demanding, as it would fail to take 
into account the burdens of such an institutional scheme. But while the alternative schemes I suggested might have disadvantages compared to roaming, it also seems clear that they serve the relevant interests reasonably well.

\subsection{Physical Health}

The problems with roaming as a means for physical health are closely similar, and we can keep discussion brief. There are well-recognized health benefits of walking and of the other activities a right to roam allows, such as skiing, hiking, and biking, so we can grant that this interest fulfills the strength criterion. ${ }^{18}$ However, it is not clear why roamers need access to private property specifically to fulfill this interest. Alternative schemes would be equally sufficient to fulfill it and would have significantly lower moral costs-for example, public subsidies for parks, trails, gyms, sports clubs, or swimming pools. Of course, these alternative schemes might not serve our interest in physical health to the same degree, or in precisely the same way, as a right to roam does, but that is no principled objection to these alternative schemes.

\subsection{Mental Health}

Anderson's next claim is that roaming nature is good for our mental health. ${ }^{19}$ "Mental health" here can be interpreted in a narrow and a broad way. In the narrow, medicalized sense, the argument would be that roaming is a good way to prevent, alleviate, or treat diagnosed mental illnesses. It is questionable, however, whether there is much evidence that roaming is good for mental health in this narrow sense (do long walks substitute for a good therapist?). Thus, for the argument to succeed, mental health must be interpreted in a broader sense, to include a wider set of psychological benefits that might come from roaming, such as peace of mind, mental tranquility, a sense of personal freedom, feeling oneness with nature, or a patriotic connection to one's Heimat ("homeland") ${ }^{20}$

There are troubles here, once again, with the strength and necessity criteria. Instead of pursuing these lines of objection, I want to highlight a different problem. Consider that some people have a strong, unquenchable desire to know

18 E.g., Bowler et al., "A Systematic Review of Evidence for the Added Benefits to Health of Exposure to Natural Environments." See Ilgunas, This Land Is Our Land, for more references to the health benefits of walking.

19 Ilgunas also stresses the physical and mental health benefits of roaming (This Land Is Our Land, chap. 6).

20 Gray, for example, marshaling a variety of poets in support, speaks loftily of nature's ability to support "self-discovery, the quest for meaning and significance, about locating oneself in time and place amidst what is often otherwise a rootless existence" (Gray, "Pedestrian Democracy and the Geography of Hope," 56). 
what is going on in other people's lives. In this descriptive sense, nosiness can be a quite psychologically strong desire. But we do not think that such an interest is morally weighty: interests in being nosy have no claim to be enshrined as moral or legal rights. The general point is that pure psychological strength is no indicator for whether some interest should be recognized as the ground for a right, as some of these interests fail important moral constraints.

One such constraint is the neutrality criterion. If the state were to recognize a right to roam on the basis of roaming's supposed tranquilizing effect, for example, then our political institutions would ascribe to a specific account of the nature of the good life. Not everyone will agree that tranquility is a desirable, or particularly valuable, state of mind; or even if everyone agrees with that claim, many people will reasonably deny that tranquility is closely connected to roaming nature or that its importance is so great as to trump the autonomy of landowners. Thus, if the right to roam were justified on any such grounds, it would be justified not on public grounds that are accessible to everyone but on a specific vision of what a good life looks like.

I think that all attempts to cash out what we mean by "mental health" in the broad sense will fall prey to this problem. There will be at least some reasonable visions of the good life on which there is no importantly strong, mental health-based interest in roaming the countryside. Insofar as we aim to develop a recognizably liberal justification of the right to roam, then, this path is barred.

\subsection{Connection to History and Culture}

Let us move on to the second-to-last interest mentioned by Anderson, roaming as a way to connect with one's history and culture. There certainly is value in having access to sites that play an important part in one's culture or history: there is value in the English seeing Stonehenge, the Greeks visiting the Acropolis, or Indians accessing the Ganges. Similarly, there are some sites that stand out for their stunning and unique natural beauty, like the Grand Canyon. For places like these, we have a strong interest in being able to access them. Furthermore, the interest also pertains to these lands specifically, as nothing else can serve as a substitute.

However, this interest once again fails the necessity criterion. What this observation establishes is a strong presumption, perhaps a requirement, that sites of cultural and historical significance or outstanding natural beauty should be accessible to everyone. Many legal systems are based on an implicit understanding that such lands should serve the public, or that if they are privately owned, there should be heavy restrictions on what can be done to the land. The right to roam, however, applies to even the most mundane of land - the kind of place 
that has never appeared on a postcard and where people put up sarcastic signs, such as "Nothing happened here on November 7, 1839."

Another way to gather support for roaming is through the vague concept of Heimat, which expresses the idea of the deep social, emotional, and cultural connection to the identity-forming surroundings in which one grew up. ${ }^{21} \mathrm{On}$ this view, not being able to wander, say, the village of one's youth or the forests and meadows of one's community would be a crucial injury to one's ability to make a place of one's own in the world. The advantage of this argument is that it plausibly succeeds on the necessity criterion. You need access to these specific lands-say, the English countryside - and access to only some of it will not do, either. However, the problem is that it fails the neutrality criterion. Aside from the vagueness of the idea, it rests on deeply contestable ideas about national and cultural ties to land, imbuing them with a mythical aura that we cannot appeal to in liberal argument.

\subsection{Sense of Community}

Lastly, sometimes the idea is advanced that roaming supports communal bonds. Ken Ilgunas, on the basis of his extensive experiences hitchhiking across the United States, argues that through roaming,

you learn that the American people are not nearly as scary and dangerous as our news stories would have us believe. You come to realize that Americans generally are hospitable, friendly, and kind. Once this realization sets in, you begin to move through the world in a lighter, more carefree way. You feel more trusting, more relaxed, more free. ${ }^{22}$

Roaming, Ilgunas argues, increases hospitality and social trust. It is a way to meet strangers and neighbors, to form social bonds, and to overcome the atomism that characterizes modern life. I leave it as an exercise to the reader to consider how this argument fails each of the three criteria so far mentioned; it seems clear to me that it does.

\section{LEFT-LIBERAL ACCOUNTS OF PROPERTY}

I have offhandedly mentioned the moral costs of the right to roam. It is now time to describe what these costs are. I will do so by outlining a left-liberal account of private property on which the right to roam looks prima facie suspicious. To avoid being dragged down by detail, I will give a generic account, not the view

21 For the notion, see Blickle, Heimat.

22 Ilgunas, This Land Is Our Land, chap. 6. 
advanced by any particular left-liberal thinker. However, I am confident that my account fairly represents mainstream left-liberal thinking about private property in political philosophy.

At its core, the left-liberal view is committed to a combination of two normative principles:

Principle of Autonomy: Our fundamental concern is to distribute opportunities to exercise one's autonomy-the ability to freely create, pursue, and realize one's own life plans. What counts as a good life is to be decided by each individual, and political institutions should not take a stance on these issues.

Principle of Distribution: Opportunities to realize one's life plans should be distributed in an equitable way (e.g., equally or in a way that benefits the worst-off or in a way that guarantees everyone a decent minimum), and political institutions should ensure that they are distributed in such a way. $^{23}$

It is now common to think of rights to private property as a bundle of rights, such that we can analytically distinguish, for example, a right to transfer property from a right to benefit from it. ${ }^{24}$ In particular, we can distinguish between rights to transfer, rights to reap benefits from, and rights to control property. The right to roam would correspond to a diminished set of landowners' rights to control their property, while it would leave other rights pertaining to their land intact. The crucial question, then, is what bundle of control-rights owners would have under the left-liberal view.

The left-liberal cannot think of the standard bundle of private property rights as including all logically possible incidents. Specifically, left-liberals will need to say that private property rights do not include rights to reap the (full) income from what one owns or the right to transfer one's property as one pleases, as achieving the aims set by the principle of distribution would otherwise become impossible. The left-liberal state needs to be able to raise taxes and, more generally, to take from some to give to others. John Christman has argued this point in

23 In this characterization, I am indebted to a similar description in Fabre, "Justice, Fairness, and World Ownership."

24 Some commentators insist that the bundle-of-rights view is uninformative or wrong (e.g., Penner, "The Bundle of Rights Picture of Property"). These "new essentialists" insist that a right to exclude forms part of the core of the concept of private property. (For a good overview, see Wyman, “The New Essentialism in Property.") I will set this debate aside, however. 
The Myth of Property, in which he rejects the "absolutist" view of private ownership on which it is a kind of absolute sovereignty over what one owns. ${ }^{25}$

One might think that a rejection of the absolutist view of ownership puts the defender of the right to roam in a good position. If transfer and benefit-reaping rights can be limited in the service of distributional aims, it seems that we can be optimistic that control rights are similarly limited. However, most left-liberals have suggested that control rights should be treated differently. ${ }^{26}$ As an example, we can turn to Dworkin's luck egalitarianism. Dworkin famously develops his theory of distributive justice through a hypothetical auction, the aim of which is to establish equality of resources. Dworkin notes, however, that such an auction is indeterminate unless bidders know what they will be able to do with their resources - that is, what rights attach to the resources they win at the auction. ${ }^{27}$

Dworkin explicitly rejects a picture on which various rights on resources are auctioned off alongside resources (such that, for example, you might bid on a tree and the exclusive right to pick its fruit).$^{28}$ Instead, he suggests that the auctioneer must divide up resources and accompany them with a fixed bundle of rights, in a way that allows for "the greatest possible flexibility in fine-tuning bids to plans and preferences," before the auction starts. ${ }^{29}$ Bidders must be allowed to bid for a profile of resources that best allows them to achieve their life plans (we can see the principle of autonomy in action here). This, Dworkin claims, is best achieved if the resources people bid for are accompanied by very strong control rights: "The principle of abstraction insists that people should in principle be left free ... to use the resources they acquire ... in whatever way they wish." ${ }^{30}$ Thus, once you acquire a resource in the Dworkinian auction, you have broad control rights over what ought to be done with it, and you do not need to specially bid for such rights.

In short, it is highly likely that rights to exclude will be a constitutive feature of property rights in a Dworkinian system. Thus, Dworkin is in agreement with right-liberal philosophers who think that the right to exclude is part of the core of ownership and that property rights are important because they allow owners

Christman calls it the "liberal" view, but I think this label is misleading. See also Murphy and Nagel, The Myth of Ownership. Including Christman, The Myth of Property.

27 Dworkin, Sovereign Virtue, 143.

Dworkin, Sovereign Virtue, 151.

Dworkin, Sovereign Virtue, 152. For a good discussion of Dworkin's principle of abstraction, see Otsuka, "Liberty, Equality, Envy, and Abstraction." 
to "set an agenda" for the things owned. ${ }^{31}$ Dworkin's disagreement with right-liberal and libertarian thinkers is primarily over how property rights should be distributed, not over the thing that should be distributed.

Even left-liberals who do not share the specifics of Dworkin's position will be strongly drawn to the outcome he reaches due to the combination of the two principles that characterize left-liberalism. Left-liberals are concerned with giving people equitable chances of leading autonomous lives. This suggests that we should assign to people that set of property rights that best allows them to realize their autonomy, subject to the constraint that everyone have equal (or otherwise justly distributed) chances of doing so. Exclusive rights over a certain part of the world seem to be an important ingredient in doing so. The right to roam takes away from landowners the ability to exclusively determine the agenda for the things they own. For this purpose, it does not matter that roaming leaves one's property and privacy largely untouched. It is the reduction in one's ability to control what one owns that is the moral insult and that is grave enough to justify exclusion. On the left-liberal picture of property, it is thus likely that we will oppose any such diminishment of control rights.

\section{A NONIDEAL ARGUMENT}

Putting the arguments from the previous two sections together, we can see that our chances of defending the right to roam on left-liberal grounds look bleak: there are significant moral costs to recognizing a right to roam and few, if any, convincing benefits that pass the test of the interest theory. I will start in this section by emphasizing the role that a right to roam can play in a nonideal world - that is, a world that is far removed from what is demanded by the principle of distribution.

The distribution of resources and, more broadly, opportunities to realize one's autonomy is enormously uneven. This is particularly true of land. In the face of these violations of the principle of distribution, we should look for feasible schemes that bring the distribution of resources and opportunities closer to the distributive ideal. The obvious way of doing so would be a large-scale redistribution of resources, or some radical change in our economic and social institutions. However, there are deep and robust political and social obstacles to such ambitious attempts to equalize resources. In the medium term, we must look for more modest, feasible policy options, even if those might not be part of the ideal package of policies that we should adopt.

It is on this ground that we can offer a first attempt to defend the right to

31 For these ideas, see Schmidtz, "Property and Justice," 80; and Katz, "Exclusion and Exclusivity in Property Law." 
roam. The right to roam provides roamers - generally speaking, the have-notswith increased opportunities to exercise their autonomy, while it takes a small smidgeon of that ability away from owners who already have ample opportunities, and much more opportunity than justice demands, to realize their autonomy. Instituting the right to roam, then, is a move toward a more equitable distribution of opportunities for autonomy under nonideal circumstances.

Encouraging evidence for the feasibility of realizing a right to roam comes from the English and Scottish cases, which implemented such schemes through statutory law relatively recently. Both nations had center-left governments who found the political capital to implement such reforms, with the Scottish law being particularly ambitious. By contrast, the alternative schemes I have discussed previously_for example, a system of public parks - would require much more time, effort, and money to realize, as they would necessitate prolonged negotiations and expensive buybacks from private owners. ${ }^{32}$

This first attempt at a nonideal argument gets the basics of a convincing justification of the right to roam correct: it must matter that we live in a world characterized by extreme distributive injustice. But the argument, as offered, is too simple. A first, general problem is that instituting a right to roam is a minor way of remedying inequality. The poor have a claim, at the bar of justice, to have their life chances improved; the freedom to traverse the lands of others seems a minor, perhaps even insultingly miniscule, moral response to that claim. One might reply that the right to roam would be part of a package of policies tackling inequality, but even then, it remains mysterious why we should put so much emphasis on it and why our political energies should not be directed elsewhere.

A second observation is that the current argument deals in two different kinds of autonomy that are hardly of the same nature and value. The autonomy that owners possess under robust right-to-exclude schemes makes them akin to small-scale tyrants over a part of the world. Under a roaming scheme, this form of autonomy is lost. But the autonomy that roamers gain in return is at best a pale cousin of this robust autonomy. A right to roam, even in its Scandinavian form, allows only a limited range of activities: it does not allow residency, commercial activity, altering the land, or determining how the land ought to be used. Roaming is certainly one form of freedom, but it seems insignificant in comparison to the autonomy of full ownership. Thus, we might worry that the current argument has a leveling-down feel to it: we take away from some (the owners) a highly valued form of autonomy, but in return no one gets to enjoy it. ${ }^{33}$

Feasibility considerations of this nature are stressed in Ilgunas, This Land Is Our Land, chap. 6. For a famous statement of the leveling-down objection in a different context, see Parfit, "Equality and Priority." 


\section{THE SYMBOLIC ARGUMENT}

Despite the weaknesses in this first attempt, we are not far from a successful argument. The core idea missing is that the right to roam serves as a symbolic inscription of a fundamental form of social equality, namely the fundamental co-ownership of all land. I will start with the first idea, of something being a symbolic inscription, before I turn to the second, more complicated notion. ${ }^{34}$

\subsection{Symbolic Inscriptions}

Let us start with an analogy. North Korea is one of the worst regimes you can imagine, and no liberal country should support such a regime politically. At the same time, North Korea has faced, and is likely to face again, humanitarian crises, especially with respect to its ability to feed its own population. What might be called for, in such a case, is a form of reluctant humanitarian aid-aid that addresses the humanitarian problem and helps the North Korean people while also expressing the serious reservations about the regime to, and through, which such aid is given.

In particular, imagine that the European Union provides food, seeds, tractors, and other machinery to North Korea as a humanitarian gift, but that it inscribes them with the slogans "Provided by the European Union" and "Freedom-Democracy_Human Rights" (in Korean). The inscriptions are symbolic: first, they express, opposing North Korean propaganda, that North Korea is not self-sufficient and that it cannot claim this help for itself; and second, they express that the aid is a reluctant gift and not an endorsement of the oppressive policies of the North Korean state. It need not detain us how realistic this example is. What is important are two features of the symbolic inscriptions. First, they do not diminish the essential usability of the aid given, in its material and economic terms: the tractors still work, the seeds still plant, the food still nourishes. What the inscriptions do, however, is to provide the aid with a certain expressive meaning: they establish certain social meanings and aim to prevent others.

Similarly, I would suggest, we can see the freedom to roam as a symbolic inscription in the rights given to property owners. The inability of landowners to keep out roamers serves as a symbolic reminder that all land is, under a left-liberal scheme, fundamentally co-owned and that landowners are in some way socially equal to nonowners (more on that idea in a moment). However, this does not diminish the core usability of private property rights in land. Those who privately own land can still decide whether it shall be field or golf course, shed or skyscraper, garden or wasteland; they can reap profits from the land, transfer it,

34 On symbolic value, see Adams, "Symbolic Value”; and Sneddon, "Symbolic Value." 
abandon it, and so forth. They can, in other words, determine the agenda for the land they own in almost any respect other than whom to keep out.

The right to roam is different, of course, from a physical inscription or object that we classically think of as symbols. As a legal rule, it is a complex social convention that expresses itself, in particular, in the behavior of public officials. ${ }^{35}$ This does not diminish its ability to bear symbolic meaning, however. What is needed for something to be legible as a symbol is some community of interpreters who roughly converge in their standards of interpretation. Legal rules are legible, in principle, in such a way, and we have no problem assigning symbolic meaning to legal rules. ${ }^{36}$

\subsection{Fundamental Co-ownership}

Second, we need to work out what the right to roam symbolizes. The obvious place to look is the left-liberal principles of justice, and in particular, the principle of distribution. Every distribution of benefits and burdens, according to that principle, needs to be justified against some distributive (patterned) ideal. This entails that no external piece of property is fundamentally owned: the possession of any piece of land is only justified insofar as it is compatible with equal opportunities for all.

Imagine that $A$ possesses some tract of land $L$. Let us imagine a simple non-luck-egalitarian account of distributive justice on which everyone is entitled to an equally valued part of the available resources in the external world. ${ }^{37}$ If so, $A$ is justified in holding $L$ just in case, and because, $L$ is part of a package of resources that has equal value to what everyone else holds. The point is that all land, like all other resources, is fundamentally co-owned, with no land being exempt from distributive claims. There is no antecedent, fundamentally private ownership of land-no procedure of acquisition, as Locke or Nozick recognize it, to make unowned land one's own. Any claim that $A$ has to $L$ is the upshot of an empirical, contingent distribution of legal rights to realize moral claims on a more fundamental level, on which no land is owned.

Fundamental co-ownership in this sense is a regulative idea, not one that expresses a historical or legal reality. In particular, the claim is not that under any current legal structure, everyone can make a claim to own all parts of the world

The background assumption here is a form of legal positivism à la Hart, The Concept of Law. I return to some of these issues in section 6.

More sophisticated egalitarian theories are likely to make the morally optimal shares of land choice sensitive, such that $A$ can possess land of higher value than $B$ if that difference goes back to voluntary choices that $A$ and $B$ have made. This would not change the basic point made in the text, however. 
in combination with all others. Whether any individual possesses legal rights in common with others depends on the particulars of an individual society's legal conventions. In its regulative function, however, fundamental co-ownership expresses an important truth about the justificatory bar against which any legally instituted system of ownership must be measured. Even if $A$ might legally possess $L, A$ must offer reasons other than initial acquisition or just transfer why he should be recognized as legally owning it. Instead, $A$ must show that the system by which we distribute the totality of external resources serves certain distributive aims.

Fundamental co-ownership in this sense expresses a form of fundamental social equality. We are not just formally equal, in that moral principles cover us equally and that there are no natural hierarchies between us. We are also fundamentally and substantively equal, in that each of our lives bears equal weight, and all differences between us must be justified to others at the bar of the liberal principles of justice. We can keep the idea of social equality vague, as a multitude of interpretations of that idea can be offered; the same goes, to a degree, for the idea of fundamental co-ownership. ${ }^{38}$ Different left-liberal conceptions will fill out these ideas in different ways, corresponding to different ways to understand the ideals of autonomy and distributive justice. But any such view, I presume, will be committed to some account of fundamental social equality with respect to external resources.

\subsection{The Symbolic Value of Roaming}

Let us connect the dots. We live in societies that do not realize, and are not remotely close to realizing, a just distribution of resources and opportunities. In such a society, limiting private property owners' control right to exclude by giving the public a right to roam is a symbolic reminder that any rights granted under our legal system are ultimately only justified against a background of social equality. Roaming does not take away owners' land or the essential usability of that land, but it reminds owners and nonowners alike of the fundamental moral claims that others have against them. It is the egalitarian thorn in a legal system that otherwise encourages hierarchical relations between haves and have-nots.

Why is there value in reminding us of fundamental social equality in our property rights? There are two parts to this question: first, why there is value of reminding us of fundamental social equality at all in our rights, and second, why there is value in doing so with respect to control rights concerning land in particular. The answer to the first part goes back to the fact that we live in a nonideal

38 For a recent account of co-ownership of the world, see, e.g., Risse, "Common Ownership of the Earth as a Non-Parochial Standpoint." 
world. A system of strong private property ownership coupled with enormous inequalities in ownership encourages an absolutist, quasi-libertarian conception of ownership - a picture on which you absolutely own what is yours and owe only slender responsibilities to the moral community.

However, there is value in reminding ourselves that any deviations from the ideal of distribution are accepted only grudgingly and temporarily until we can achieve a better distribution. The error of the Dworkinian left-liberal is precisely to think that a change in the principle of distribution leaves the things to be distributed unchanged. Symbolic reminders leave the essential usability of property intact, thus granting owners a still significant amount of autonomy, while also highlighting the fundamentally egalitarian basis on which any claim to property is justified.

The second part, then, is why we should symbolically remind ourselves of social equality through control rights concerning land in particular. After all, there are many different ways in which we could institute symbolic reminders. There is no deep, a priori answer to be offered in response, only a series of observations based on the common workings of human society. First, insofar as we all need space to live and realize the many valuable activities of human life, land appears as a finite and scarce precondition for achieving valuable lives. Second, most societies tie economic wealth, security, and social recognition closely to land ownership. Inequality in land ownership — and our inability to access private land in particular-is one of the most visible ways in which wider social and economic inequalities express themselves in many societies. All this makes land a focal resource worth regulating for the left-liberal.

\section{OBSERVATIONS AND OBJECTIONS}

I will now consider some advantages of this argument, as well as respond to some objections.

\subsection{Interests, Again}

I argued that the interest-based argument failed because the proposed interests grounding a right to roam were not important enough, were inaccessible within public reason, or failed the necessity requirement. The revised nonideal argument has no similar weaknesses. First, a right to roam is not directly justified on the basis of anyone's interests in roaming. Instead, it is justified with reference to a fundamental liberal principle of justice. These principles do not commit us to any particular conception of the good life, and thus pass the neutrality requirement. In the same way, we can answer the worry that the right to 
roam does not rest on moral considerations that are weighty enough. On the argument considered, the right to roam is a symbolic reminder of an important liberal principle-namely, the fundamental co-ownership of the world. Lastly, the argument answers why a universal right to roam, rather than, say, specific easements or public-private partnerships, is necessary. None of these alternative schemes symbolically denotes all land as being fundamentally co-owned; indeed, public-private partnerships reinforce the notion that the sovereignty of owners is in some way supreme.

Still, interests play some role in the current argument. There are different ways that the fundamental co-ownership of the world could be symbolically represented in our legal norms and conventions, some of which serve our interests more than others. Another way we could symbolically represent social equality, for example, is to give everyone ownership of an equal plot of land on the moon. ${ }^{39}$ We can assume for argument's sake that moon co-ownership works just as well symbolically as a right to freely roam the earth. Of course, no one's tangible interests are served by having a plot of land on the moon. That the right to roam not only symbolically represents social equality but also serves important interests thus gives us reason to prefer it over moon co-ownership. That roaming serves interests thus enhances the argument for it, without being its primary foundation.

\subsection{Autonomy, Again}

We can also review the symbolic argument in light of the failures of the simple nonideal argument (section 4). The first objection was that roaming seems like a minor and insignificant remedy for the pressing inequalities we face. The advantage of the current argument is that it does not justify roaming as a serious attempt to remedy distributional equality through redistribution. Rather, roaming is offered as important in its symbolic capacity. Thus, even if the right to roam did not shift burdens and benefits in a meaningful way toward equality, we could still justify it on the basis of its symbolic capacity.

What about the suspicion that roaming leads to a repugnant form of leveling-down, by making it impossible for anyone to realize the superior form of autonomy that comes with full control rights over land? Here, I think, the left-liberal defender of the symbolic argument should, to a degree, bite the bullet. Under a roaming scheme, you cannot unilaterally say no to others entering your property. (Note, however, the many exceptions: you can still say no to others invading your privacy or diminishing the economic viability of your land, etc.) Thus, we all lack a certain kind of strong autonomy over our own property.

39 I owe this example to an anonymous reviewer. 
Lacking complete autonomy in this sense is precisely the symbolic reminder of our falling short of an equitable distribution of resources.

\subsection{Further Doubts about Symbolism}

We need to be careful in distinguishing the symbolic meaning of some legal rule (i.e., how a competent interpreter in a given community would understand it) from its expected impact on social conventions (i.e., how that legal rule being in force is likely to impact the behavior and beliefs of individuals subject to that rule).$^{40}$ I have suggested that a right to roam would be an important symbol. However, one might now raise doubts of two kinds: (i) whether the symbol would be recognized in its intended role, and (ii) whether, even if it were recognized in its intended role, it would have any significant effects on changing social conventions and behavior.

With respect to the first doubt, we should admit that the mere existence of a right to roam, as a legal rule, is probably insufficient for that right to be interpreted as a symbol for social equality. There could be societies that allow roaming but do not symbolically interpret it to express any kind of social equality. To be successful, the right to roam requires a larger social, cultural, and political context that makes the rule symbolically legible in the right way.

We can even imagine scenarios in which the right to roam is perceived opposite from the way it is intended, in a fashion detrimental to left-liberalism. Perhaps the right is interpreted, for example, as a symbol of disrespect for autonomy, or in favor of state paternalism, or as some other form of overbearing state interference. If this perception is widespread and does not rest on willful ignorance or misinterpretation of the policy, then it speaks against adopting the right to roam. ${ }^{41}$

Inversely, we can imagine that anti-egalitarian arrangements are interpreted in an egalitarian fashion. Imagine that a private company starts buying up large tracts of land, finally becoming a monopoly in a certain area, and calls itself "The People's Land." The company advertises itself (misleadingly) as not being interested in profit and uses the slogan, "The People's Land Belongs to Everyone." We can imagine that such advertising contributes to a perception that its land is indeed owned by its leaseholders. Some observers might mistake "The People's Land" for a public service and falsely believe that it has egalitarian aims it

The point is stressed in Adler's critique of expressive theories of law ("Expressive Theories of Law").

41 For this paragraph and the next two, I am indebted to very insightful objections from an anonymous reviewer. The idea of "The People's Land," in particular, is adapted from their comments. 
does not in fact have. We can assume that residents on “The People's Land” will perceive each other to be highly socially equal to each other, even though there is an extreme difference in wealth between them and the owners of the holding company.

If symbolism possesses any independent weight, then it seems that left-liberals should at least sometimes endorse a social institution like "The People's Land," even though it is detrimental to substantive egalitarian aims. This is a counterintuitive result. I think our answer must be that the value of symbols is subject to some internal coherence requirement, such that symbols must be compatible, in some way, with the things they mean to symbolize. On this view, some symbol $X$ representing a thing $Y$ possesses independent value only if $Y$ is intrinsically valuable and $X$ itself is compatible with $Y$. On this view, there would be no independent value in "The People's Land," because the operation of this institution contradicts the value it is meant to symbolize. The right to roam, on the other hand, does not obviously violate the coherence requirement. Thus, there is independent value in legally recognizing such a right. ${ }^{42}$

Putting such scenarios aside, I am confident that we can find the cultural resources, at least within Western legal cultures (which I know best), that allow the right to roam to be interpreted in an egalitarian fashion. The Land Reform (Scotland) Act 2003, for example, was certainly perceived as a model to equalize access to land, and it built on (among other things) an important historical tradition in which the Scottish Highlands were perceived to be owned by the Scottish people in common. ${ }^{43}$ Moreover, even if such resources for interpretation do not exist in a given society, they can be created-first and foremost, politically. Instituting a right to roam would then be part of a larger campaign of reforming the perception of property rights.

We should also admit that a legal rule like the right to roam has neither a single nor an unambiguous symbolic meaning. Instead of the technical notion of fundamental co-ownership, a right to roam is likely to be understood also in vaguer terms of equality, democracy, shared heritage, or community. What matters, however, are not the precise labels that would be used in interpretation but whether a legal right favoring roamers overall sends a message that endorses, or is at least compatible with, the principle of fundamental co-ownership.

Another worry is the second-namely, even if roaming is interpreted in its intended fashion, it remains a powerless symbol. What would roaming matter, of further questions that we would need to tackle. But I will set these issues aside.

43 For a highly sympathetic treatment of the Scottish case along these lines, see Alexander, "The Sporting Life." Cf. Lovett, "Progressive Property in Action." 
this objection goes, if it did not incline anyone to act or think in more egalitarian ways? The reply to this objection, I think, should be twofold. First, changing behavior is not the primary object of a symbolic reminder. Think back to the humanitarian aid given to North Korea by a reluctant European Union. It would certainly be a problem if the symbolic inscription were not recognized at all. At the same time, there is no expectation of success in significantly changing the North Korean government or its policies. Similarly, if the right to roam can be recognized as a slight to quasi-libertarian perceptions of property rights, and sometimes it does get recognized in such a way, this might be sufficient to fulfill its purpose.

However, if the right to roam really turned out to be a fundamentally powerless symbol, which engaged the members of a given society so marginally as to not significantly change anyone's behavior or perception, then we should indeed rethink its aptness. Where the social and cultural context is such that reminders of the fundamental co-ownership of the world are best expressed through alternative means, those should be chosen. But while it is a limitation, I think this is not a weakness: it simply shows that the argument is sensitive to concrete social and cultural contexts, as it should be.

\section{CONCLUDING REMARKS}

In lieu of a summary, let me finish by noting some open questions.

First, I have not defended the left-liberal view of property rights. The argument of this paper is thus one internal to left-liberalism (which, I should add, I am not myself committed to in many respects). Further philosophical work would look at how this argument plays out in the context of different left-liberal accounts of justice. I have mostly operated, for example, with an egalitarian principle of distribution; we might wonder what would change in the argument if we move to a more sufficientarian account.

Second, following much of the literature on the right to roam, I have implicitly conceived of it as applying in a rural context, as the right to roam nature. But we might ask whether there are not also implications in an urban context. For example, we might think that a similar argument can be hoisted against gated communities or the privatization of public amenities.

Lastly, we can also consider whether the argument I have given can be extended to other practical contexts. The most general lesson of the paper is that the left-liberal principle of distribution should also affect, via the inclusion of symbolic reminders, the things to be distributed. If I am correct, then all rights should bear symbolic inscriptions of their egalitarian purpose. This is likely to 
have implications for the ownership of other external resources-for example, the means of production - as well as how certain services and opportunities should be offered, such as education. But tracing these implications is the story for another day. ${ }^{44}$

Ludwig-Maximilians-Universität Munich mail@matthiasbrinkmann.de

\section{REFERENCES}

Adams, Robert Merrihew. "Symbolic Value." Midwest Studies in Philosophy 21, no. 1 (September 1997): 1-15.

Adler, Matthew. "Expressive Theories of Law: A Skeptical Overview." University of Pennsylvania Law Review 148, no. 5 (May 2000): 1363-501.

Alexander, Gregory S. "The Sporting Life: Democratic Culture and the Historical Origins of the Scottish Right to Roam." University of Illinois Law Review 2016, no. 2 (2016): 321-70.

Anderson, Jerry L. "Britain's Right to Roam: Redefining the Landowner's Bundle of Sticks." Georgetown International Environmental Law Review 19, no. 3 (2007): $375-436$.

Blickle, Peter. Heimat: A Critical Theory of the German Idea of Homeland. Rochester, NY: Camden House, 2004.

Bowler, Diana, Lisette Buyung-Ali, Teri Knight, and Andrew Pullin. "A Systematic Review of Evidence for the Added Benefits to Health of Exposure to Natural Environments." BMC Public Health 10, no. 456 (2010).

Christman, John Philip. The Myth of Property: Toward an Egalitarian Theory of Ownership. New York: Oxford University Press, 1994.

Cruft, Rowan. "Against Individualistic Justifications of Property Rights." Utilitas 18, no. 2 (June 2006): 154-72.

Dominiak, Łukasz. "Must Right-Libertarians Embrace Easements by Necessity?" Diametros 16, no. 60 (June 2019): 34-51.

Dworkin, Ronald. Sovereign Virtue: The Theory and Practice of Equality. Cambridge, MA: Harvard University Press, 2002.

Fabre, Cécile. "Justice, Fairness, and World Ownership." Law and Philosophy 21, no. 3 (May 2002): 249-73.

44 I am thankful to Amin Ebrahimi and an anonymous reviewer for this journal for helpful comments. 
Gray, Kevin. "Pedestrian Democracy and the Geography of Hope." Journal of Human Rights and the Environment 1, no. 1 (March 2010): 45-65.

Gray, Kevin, and Susan Francis Gray. "Civil Rights, Civil Wrongs and Quasi-Public Space." European Human Rights Law Review 4 (1999): 46-102.

- L Land Law. 7 th ed. Core Text Series. Oxford: Oxford University Press, 2011.

Hart, H.L.A. The Concept of Law. Oxford: Clarendon Press, 1961.

Ilgunas, Ken. This Land Is Our Land: How We Lost the Right to Roam and How to Take It Back. New York: Penguin, 2018.

Katz, Larissa. "Exclusion and Exclusivity in Property Law." University of Toronto Law Journal 58, no. 3 (Summer 2008): 275-315.

Klick, Jonathan, and Gideon Parchomovsky. "The Value of the Right to Exclude: An Empirical Assessment." University of Pennsylvania Law Review 165 (2016): 917-66.

Kochan, Donald. “The Market to Roam: Using Sharing Economy Platforms for Expanding Roaming Access to Land Resources." Natural Resources Journal 59, no. 1 (Winter 2019): 89-134.

Kramer, Matthew H. "Some Doubts about Alternatives to the Interest Theory of Rights." Ethics 123, no. 2 (January 2013): 245-63.

Lovett, John. "Progressive Property in Action: The Land Reform (Scotland) Act 2003." Nebraska Law Review 89, no. 4 (2010): 739-818.

Murphy, Liam, and Thomas Nagel. The Myth of Ownership: Taxes and Justice. Oxford: Oxford University Press, 2002.

Otsuka, Michael. "Liberty, Equality, Envy, and Abstraction." In Dworkin and His Critics: With Replies by Dworkin, edited by Justine Burley, 70-78. Philosophers and Their Critics 11. Malden, MA: Blackwell Pub, 2004.

Parfit, Derek. "Equality and Priority." Ratio 10, no. 3 (December 1997): 202-21. Penner, J.E. “The Bundle of Rights Picture of Property." UCLA Law Review 43, no. 3 (1996): 711-820.

Raz, Joseph. "On the Nature of Rights." Mind 93, no. 370 (April 1984): 194-214. Risse, Mathias. "Common Ownership of the Earth as a Non-Parochial Standpoint: A Contingent Derivation of Human Rights." European Journal of Philosophy 17, no. 2 (June 2009): 277-304.

Robertson, Heidi Gorovitz. "Public Access to Private Land for Walking: Environmental and Individual Responsibility as Rationale for Limiting the Right to Exclude." Georgetown International Environmental Law Review 23, no. 2 (2011): 211-62.

Rose, Carol. "The Comedy of the Commons: Custom, Commerce, and Inher- 
ently Public Property." University of Chicago Law Review 53, no. 3 (Summer 1986): 711-81.

Sawers, Brian. "The Right to Exclude from Unimproved Land." Temple Law Review 83, no. 3 (Spring 2011): 665-96.

Schmidtz, David. "Property and Justice." Social Philosophy and Policy 27, no. 1 (January 2010): 79-100.

Shoard, Marion. A Right to Roam. Oxford: Oxford University Press, 1999.

Sneddon, Andrew. "Symbolic Value." Journal of Value Inquiry 50, no. 2 (June 2016): 395-413.

Sreenivasan, Gopal. "Duties and Their Direction.” Ethics 120, no. 3 (April 2010): 465-94.

Sténs, Anna, and Camilla Sandström. "Allemansrätten in Sweden: A Resistant Custom." Landscapes 15, no. 2 (November 2014): 106-18.

Tasioulas, John. "On the Foundations of Human Rights." In Philosophical Foundations of Human Rights, edited by Rowan Cruft, S. Matthew Liao, and Massimo Renzo, 45-70. Oxford: Oxford University Press, 2015.

Wellman, Carl. The Proliferation of Rights: Moral Progress or Empty Rhetoric? Boulder, CO: Westview Press, 1999.

Wyman, Katrina M. “The New Essentialism in Property.” Journal of Legal Analysis 9, no. 2 (Winter 2017): 183-246. 